NASA Technical Memorandum 107305

AIAA-96-2720

\title{
NSTAR Ion Thruster and Breadboard Power Processor Functional Integration Test Results
}

John A. Hamley, Luis R. Pinero, Vincent K. Rawlin, and John R. Miller Lewis Research Center

Cleveland, Ohio

Roger M. Myers

NYMA Inc.

Cleveland, Ohio

Glen E. Bowers

Gilcrest Electric

Elyria, Ohio

Prepared for the

32nd Joint Propulsion Conference

cosponsored by AIAA, ASME, SAE, and ASEE

Lake Buena Vista, Florida, July, 1-3, 1996

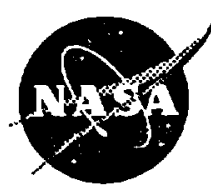

National Aeronautics and

Space Administration 


\title{
NSTAR ION THRUSTER AND BREADBOARD POWER PROCESSOR FUNCTIONAL INTEGRATION TEST RESULTS
}

\author{
John A. Hamley, ${ }^{*}$ Luis R. Pinero, ${ }^{*}$ Vincent K. Rawlin, $\dagger$ and John R. Miller** \\ NASA Lewis Research Center \\ Cleveland, Ohio 44135 \\ Roger M. Myers ${ }^{\dagger \dagger}$ \\ NYMA Inc. \\ Cleveland, Ohio 44135 \\ Glen E. Bowers*** \\ Gilcrest Electric \\ Elyria, Ohio 44035
}

\begin{abstract}
A $2.3 \mathrm{~kW}$ Breadboard Power Processing Unit (BBPPU) was developed as part of the NASA Solar Electric Propulsion Technology Application Readiness (NSTAR) Program. The NSTAR program will deliver an electric propulsion system based on a $30 \mathrm{~cm}$ xenon ion thruster to the New Millennium (NM) program for use as the primary propulsion system for the initial NM flight. The final development test for the BBPPU, the Functional Integration Test, was carried out to demonstrate all aspects of BBPPU operation with an Engineering Model Thruster. Test objectives included 1) demonstration and validation of automated thruster start procedures, 2) demonstration of stable closed loop control of the thruster beam current, 3) successful response and recovery to thruster faults, and 4) successful safing of the system during simulated spacecraft faults. These objectives were met over the specified 80-120 VDC input voltage range and 0.5-2.3 output power capability of the BBPPU. Two minor anomalies were noted in discharge and neutralizer keeper current. These anomalies did not affect the stability of the system and were successfully corrected.
\end{abstract}

\section{Nomenclature}

$\mathrm{J}_{\mathrm{A}} \quad$ Accelerator Current, $\mathrm{mA}$
$\mathrm{J}_{\mathrm{B}} \quad$ Beam Current, $\mathrm{A}$

$\mathrm{J}_{\mathrm{D}} \quad$ Discharge Current, $\mathrm{A}$

$\mathrm{J}_{\mathrm{NK}} \quad$ Neutralizer Keeper Current, A

$\mathrm{V}_{\mathrm{A}} \quad$ Accelerator Voltage, $\mathrm{V}$

$V_{B} \quad$ Beam Voltage, $V$

$V_{D}$ Discharge Voltage, $V$

$\mathrm{V}_{\mathrm{NK}} \quad$ Neutralizer Keeper Voltage, $\mathrm{V}$

\section{Introduction}

A flight electric propulsion system based on $30 \mathrm{~cm}$ xenon ion system technology is being developed under the NASA Solar Electric Propulsion Technology Applications Readiness (NSTAR) program. The NSTAR program will deliver a $30 \mathrm{~cm}$ thruster, Power Processing Unit (PPU), Digital Control and Interface Unit (DCIU), and Xenon Feed System (XFS) for integration on the first New Millennium Spacecraft.1,2 As part of the NSTAR program, a Breadboard Power Processing Unit (BBPPU) and several Engineering Model Thrusters (EMTs) were developed prior to the award of a contract for flight hardware.

NSTAR engineering model thrusters incorporate several innovations with respect to the state of the art in ion technology. These innovations include a conical, spun aluminum, integral thruster body/anode, elimination of

\footnotetext{
* Electrical Engineer, On-Board Propulsion Branch, 21000 Brookpark Rd., MS 301-3

† Electrical Engineer, On-Board Propulsion Branch, 21000 Brookpark Rd., MS 301-3, Member AIAA

** Electronics Technician, Energy and Spacecraft Branch, 21000 Brookpark Rd., MS 301-1

t† Deputy Director, Aerospace Technology Department, 2001 Aerospace Pkwy., 44142, Member AIAA

*** Electronic Systems Mechanic, 570 Ternes Ave
} 
magnetic metals in the thruster body, and biasing the cathode keeper electrode through a $1 \mathrm{k} \Omega$ resistor connected between the keeper and anode. This method of keeper biasing eliminated the need for a dedicated cathode keeper power supply. Technologies pertaining to cathode ignition and life were also transferred from the Space Station Plasma contactor program. The result was a $2.3 \mathrm{~kW}, 30 \mathrm{~cm}$ thruster with a mass of only 7 $\mathrm{kg}$. NSTAR thruster and plasma contactor cathode technology have been described in detail elsewhere. ${ }^{3-6}$

The BBPPU incorporates "dual use" power supplies for the neutralizer and main cathodes. These power supplies provided two switchable outputs tailored to power both the thruster heaters and anode discharges. Discharge ignition was accomplished with a high voltage pulse transformer integral with the output filter inductor in these power supplies. This form of pulse ignition was first demonstrated successfully in arcjet power electronics. ${ }^{7}$ A microcontroller was utilized to sequence the operation of all thruster power supplies and provide closed loop control of the thruster beam current via adjustment of the thruster discharge current. The BBPPU controller automates the thruster cathode conditioning, ignition, transition to steady state, and throttling between sixteen user-programmable throttle points. Control of the xenon feed system was not included in the BBPPU control software, and is resident in the DCIU for the flight system. The NSTAR BBPPU has been described in detail elsewhere.8,9

As has been demonstrated in several previous programs, one of the most critical tests in the development of an ion propulsion system is the initial integration test of the thruster and BBPPU.10,11 In these tests the thruster control laws, power supply functionality, overall stability, and system performance are evaluated. In the case of the NSTAR system, several power supplies must operate in unison, performing discrete regulation of thruster parameters without crosstalk. Further, several procedures which are under the control of the system microcontroller including the automatic start of the thruster and closed loop control of the thruster beam current must be validated. This paper presents the test objectives, procedure, and results of the NSTAR Functional Integration Test (FIT), which was the first integration of the BBPPU with an EMT. The results of this test were immediately provided to the flight hardware developer for incorporation into the final PPU design.

\section{Test Objectives}

The fundamental objective of the FIT was to demonstrate the specified functional performance of the integrated EMT and BBPPU combination. To fulfill this objective, the operation of the integrated EMT and BBPPU was evaluated over the required power throttle and BBPPU input voltage range by characterizing the integrated EMT and BBPPU response to startup, shutdown, and power setpoint commands. Based on the results of the test, required design changes to the EMT and BBPPU would be identified and implemented to achieve the specified system functional performance.

\section{ETT Hardware}

\section{Test Articles}

Engineering Model Thruster \#2 (EMT 2), was used as the test thruster. EMT 2 incorporated all engineering changes made to the NSTAR thruster based on data from 2000 and 1000 hour lifetests of EMT 1,3,12 conducted as precursors to a planned 8000 hour lifetime validation test of EMT 2. A simplified schematic of the thruster appears in Figure 1. Power was brought to the thruster via seven wires. A single wire from the thruster connected the discharge anode to the positive output of the beam and discharge power supplies. A new feature for EMT 2 was a cathode keeper electrode, which was biased from cathode common by a connection to the discharge anode through a $1 \mathrm{k} \Omega$ resistor. Potential leads, not shown in the figure, were used to measure the discharge voltage. Xenon propellant was provided through three feed lines, one for each cathode and one for the discharge chamber. Detailed descriptions of the thruster are available elsewhere. 3,4

A block diagram of the NSTAR BBPPU appears in Figure 2. Power was input to the PPU via two separate power busses, a 28 VDC regulated bus, which powered all housekeeping functions including the microcontroller, and an $80-120 \mathrm{VDC}$ high power bus which supplied power to the four power converters which operated the thruster. The discharge and neutralizer power supplies employed a dual use topology to allow the cathode heater power to be derived from the same converter which supplied power to the corresponding anode. These power supplies were parallel converters with a switching frequency of $50 \mathrm{KHz}$. High voltage ignition pulses which were used to initiate the thruster discharges were generated by a pulse transformer which also acted as the output filter for the supplies.? The beam and accelerator power supplies were separate physically, but were controlled in unison during thruster operation. The beam power supply was a full bridge, zero-voltage switched converter with a switching frequency of $50 \mathrm{KHz}$. Four secondaries with dedicated bridge rectifier circuits were placed in series to generate 
the $1100 \mathrm{~V}$ beam power output. The low output power of the accelerator power supply enabled a $50 \mathrm{kHz}$ flyback topology to be utilized. A microcontroller $(\mu \mathrm{C})$ was used to automate the cathode conditioning, thruster start, and steady state operation of the thruster. Sixteen pre-programmed power levels were available for thruster operation. These were stored internal to the $\mu \mathrm{C}$. A single command was available to start the thruster and maintain steady state operation at any of these power levels. The data in the throttling table was modifiable by another command. A sample throttling table is shown in Table 1. Cathode and main flow rates ranged from $2.1 \mathrm{sccm}$ to $3.0 \mathrm{sccm}$ and 6.0 to $23.5 \mathrm{sccm}$, respectively. The $\mu \mathrm{C}$ also digitized all analog power supply outputs and power supply status bits and transmitted the telemetry data over an RS-232 data link to a command and telemetry display terminal. Detailed descriptions of the NSTAR BBPPU, its functions, and operation are available elsewhere. ${ }^{8.9}$

A laboratory feed system with commercial xenon flow controllers and meters was used. The test procedure was written such that the behavior of the laboratory XFS was similar to that of the flight system. The response time of the commercial flow controllers, which was on the order of a few seconds, was much faster than those expected from the anticipated flight system. The flight system, which regulates flow rate by maintaining a constant pressure in a plenum that is connected to a flow restrictor, has a response time on the order of several minutes. Thus, the BBPPU beam current regulator control loop was given a conservative case test for stability when encountering time varying xenon flow to the thruster.

\section{Data Acquisition}

Three methods of data acquisition were utilized in the FIT. Digital Multimeters (DMMs) were used to directly measure all thruster voltages and currents. To eliminate the effects of cable losses, potential leads were attached to the thruster anode and main cathode to read the discharge voltage. The digital thruster data acquired by the BBPPU $\mu \mathrm{C}$ was stored at regular intervals on a hard disk drive connected to the BBPPU command and data terminal. In addition, the BBPPU also provided drivers for a strip chart recorder. The strip chart data are presented in the Results and Discussion section of this report.

\section{Test Facility}

The EMT was mounted on the centerline of the large space propulsion testbed at NASA LeRC (VF 5). VF 5 is a $4.6 \mathrm{~m} \times 19.5 \mathrm{~m}$ cryopumped facility with a xenon pumping speed on the order of $300,000 \mathrm{l} / \mathrm{s} .{ }^{13}$ A block diagram of the test setup appears in Figure 3.

\section{BBPPU Operation}

Of primary concern in the FIT was the operation and stability of the automated procedures in the BBPPU over the required input voltage and output power range. Prior to the FIT, the individual power supplies in the BBPPU had already been integrated with a Functional Model Thruster (FMT) ${ }^{9}$ The individual power supplies were also integrated into a single unit and operated with an FMT under manual control in previous developmental tests. Thus, the stability of the individual power supply control loops were proven to be stable. However, integration of the breadboard with the microcontroller resulted in some modifications to the power supplies to improve the noise immunity of the analog control voltages in the breadboard. These modifications were to later prove troublesome, and corrective actions were needed to return the BBPPU to specifications.

\section{Thruster Start Procedure}

Prior to thruster start, the flow rates are set to the values commensurate with full power operation, and the neutralizer and discharge power supplies are set to the heater output mode. The cathode heaters are energized for six minutes at full heater power. After six minutes, the neutralizer power supply is shut down, switched to anode mode and restarted with the pulse ignitor active. If the neutralizer cathode plasma discharge starts, the discharge power supply is shut down and restarted in a similar fashion. After discharge ignition, the thruster is allowed to operate without beam extraction for twenty seconds to allow the discharge plasma to stabilize. After the twenty second warm-up period, the high voltage is applied and the throttling algorithm adjusts the beam current to the proper value. Power supply setpoints are restricted to those assigned to power level 1 in the throttling table.

Each cathode is given 20 seconds to start with the high voltage ignitor. If the cathode fails to start, the BBPPU recycles back to the beginning of the six minute preheat period and attempts to start the cathodes again. If a cathode does not start in three attempts, the BBPPU controller shuts down the BBPPU, displays a warning message on the telemetry terminal, and waits for operator intervention.

\section{Beam Current Regulator}

The beam current regulator loop relies on the proportionality of the beam current to the discharge current at a fixed flow rate. The beam current is 
measured at a rate of one sample per second and is compared to the desired value. If the beam current is in error, the discharge current is adjusted in proportion to the error. The maximum permissible discharge current adjustment is limited to $100 \mathrm{~mA}$. In the event that the beam current is unstable, or below $250 \mathrm{~mA}$, the discharge current is not adjusted.

\section{Throttling Algorithm}

The throttling algorithm for the FIT was identical to that planned for the flight unit. Because the BBPPU controller has no control authority over the feed system, flow at the appropriate rate to the thruster is assumed.

To throttle to a higher power level, the feed system is first commanded to the flow rate for the new operating point. When the flow rate stabilizes, the throttle up command is then sent to the BBPPU. The BBPPU responds by first increasing the beam and accelerator voltages to the new values in the throttling table. The beam current is then increased by the closed loop beam current regulation algorithm, which begins regulation at the new setpoint. The operation of the beam current regulator is described in detail in the following section.

Throttle down reverses the process. The discharge power supply output current is commanded to the new value in the throttling table, and the beam current regulator begins to regulate the current at the new value. When the beam current is stable within $\pm 0.015 \mathrm{~A}$ of the final value, the beam and accelerator voltages are reduced to their new values, if necessary. When the thruster is electrically stable, the flow rates are adjusted to their new levels.

\section{High Voltage Recycles}

The following thruster faults require the BBPPU to take corrective action: 1) $\left.J_{b}>3 A, 2\right)$ neutralizer extinction, or 3) discharge extinction. Upon detection of a fault, the beam and accelerator power supplies are immediately shut down and the discharge current is commanded to 4 A. Following a $500 \mathrm{~ms}$ delay, the high voltage is reapplied only if both thruster discharges are lit and another $500 \mathrm{~ms}$ delay follows. The discharge current is then ramped back to its original value. In the event that the recycle was caused by a discharge extinction, BBPPU shuts down and awaits further operator intervention.

\section{EIT Procedure}

System power-up was initiated with the data terminal. The 28 VDC housekeeping power was applied to the
BBPPU and communication between the BBPPU and data terminal was verified. The 80-120 VDC input power supply was set to 100 VDC output and powered on. The main and cathode flow rates were set to the levels required for the $2.3 \mathrm{~kW}$ power level. The operating points selected for the FIT are listed in Table 1. For the FIT, the thruster was started at power level 1 and throttled up in power in the discrete steps indicated in Table 1.

The command to operate the thruster at power level 1 was sent. This started the thruster at the lowest available power level of $0.5 \mathrm{~kW}$. After the thruster was operating, flow rates were adjusted to levels appropriate for low power operation. No flow adjustments were necessary for the next operating point so the BBPPU was commanded to increase power to power level 2. Following stabilization at this power level, data were taken and the BBPPU was commanded to throttle up to power level 3, and the data acquisition process was repeated.

Prior to throttling to power level 5, a flow adjustment was made to ensure adequate flow to the thruster during the power increase. The process was repeated and the thruster was operated at power levels 10 and 15 . While the thruster was operating at $2.3 \mathrm{~kW}$ input, several thruster faults requiring high voltage recycles were manually simulated including anode to tank ground, anode to accelerator grid, accelerator grid to ground, and cathode common to ground. BBPPU behavior during these faults was recorded on a high speed digital oscilloscope.

With the steady state performance evaluation at $100 \mathrm{~V}$ thus completed, the thruster was commanded off. The input voltage to the BBPPU was reduced to 80 VDC and the process repeated to evaluate BBPPU performance at the lower input voltage limit. One more set of data was taken with the input voltage set to the upper input limit of 120 VDC.

Following steady state operation demonstration, several faults were induced to characterize the BBPPU microcontrollers ability to detect and recover from these faults. The input voltage to the BBPPU was set at 100 VDC, and the neutralizer keeper lead was disconnected to preclude thruster ignition. The command was sent to operate the thruster at power level 1 and the BBPPU reaction was recorded. The neutralizer keeper lead was reconnected, and the thruster started. Thruster power was throttled up to power level 10 and a shorting bar was held across the anode terminal and facility ground for ten seconds. The shorting bar was then released and the 
recovery to steady state operation characterized. Finally, with the thruster operating at power level 15 , the 80 120 VDC bus power was removed, and the DCIU microcontroller reaction to this fault was observed.

Finally, the throttle up time from startup to steady state operation at high power was characterized to determine the total amount of time necessary to start a "cold" thruster.

\section{Results and Discussion}

A large amount of data was generated while the FIT was being conducted. For brevity, only the data at 100 VDC BBPPU input and selected fault recovery data will be presented here. The data at 100 VDC input were typical of all of the data collected.

Figure 4 is the strip chart record of a typical thruster start. The data from the cathode preheat is not shown. Cathode heater power was simultaneously applied to both cathodes for six minutes. After the six minute preheat, the BBPPU $\mu \mathrm{C}$ turned off the neutralizer power supply, switched the output to anode mode and turned the supply back on with the pulse ignitor. Neutralizer ignition was immediate, with some overshoot in the neutralizer current. The peak neutralizer current was 4 A, but lasted only $60 \mathrm{~ms}$. This short duration overshoot was determined to be inconsequential to the cathode. The neutralizer current quickly stabilized at the $1.5 \mathrm{~A}$ setpoint. Five seconds later, the main cathode heater power was removed, and the discharge power supply reenergized in the anode mode. A similar overshoot was observed in the discharge current, but the power supply settled at the 4 ADC setpoint within $60 \mathrm{~ms}$. A twenty second discharge stabilization period followed prior to the application of the high voltage. Both beam and accelerator power supplies were powered on simultaneously, and the accelerator supply was allowed to overshoot by design. There was no overshoot in the beam power supply. Closed loop control of the beam current was immediately engaged and the regulator adjusted the current to the $0.54 \mathrm{~A}$ setpoint within 30 seconds. A reduction in neutralizer keeper voltage was observed when beam extraction began. This was expected due to the higher neutralizer emission current with beam extraction.

Following the thruster start, the flow rate to the thruster was reduced from the full power setpoint to the power level 1 setpoint. The flow adjustment was completed in approximately 38 seconds. Figure 5 shows a strip chart record of the thruster parameters during the flow adjustment. As expected, the discharge voltage rose with the flow rate reduction, and the accelerator impingement current was reduced. The beam current showed a modest deviation of $50 \mathrm{~mA}$ during this period. This deviation was largely due to the rapid change in thruster flow rate, which was at least one order of magnitude faster than would be expected with the flight system.

Throttling from power level 1 to 2, shown in Figure 6, did not involve any adjustments to the thruster flow. The increase in power at this level was accomplished by an adjustment in beam voltage only. Upon receipt of the throttle up command, the BBPPU increased the beam voltage from 650 to 850 VDC in approximately 20 seconds. During this transition, the thruster beam current remained constant. A slight decrease in discharge current was commanded by the beam current regulator to compensate for the increase in total accelerating voltage and subsequent increase in ion extraction efficiency. The transition to power level 3 from power level 2 required an increase in beam voltage to $1100 \mathrm{VDC}$ and was accomplished without a change in the xenon flow. The reaction of the thruster parameters were identical to those shown in Figure 6. Subsequent throttling to higher power levels required increases in both flow rate and discharge current to allow the beam current to increase to the higher levels.

Figure 7 shows the effects of both the flow rate increase and the throttle up in engine power from level 3 to 5 . Approximately 15 seconds were required to adjust the flow rate to the new level. During this time period, a slight increase in beam current was noted, but the closed loop regulator returned the beam current to the original setpoint within 10 seconds. This was illustrated by the reduction in discharge current. Upon receipt of the throttle up command, the discharge current began to ramp up to increase the beam current to the new value. The throttle up was complete within 30 seconds, and no overshoot in beam current was noted.

A xenon flow rate increase was again needed for the throttle up to power level 10 . This was accomplished in 10 seconds, and this rapid change caused a perturbation in the beam current, as shown in Figure 8. Upon receipt of the throttle up command, the accelerator voltage was decreased in a stepwise fashion to $-180 \mathrm{~V}$ prior to the increase in beam current. This was to ensure that the increase in beam current did not approach the electron backstreaming limit of the grids. After receipt of the throttle up command, the discharge current began to ramp up until the beam current reached the targeted value. Shortly after the throttle up was complete, a high voltage fault and recycle occurred. The BBPPU recovered correctly, and the beam current was restored to its 
original value.

The throttle up to power level 15 was identical to the power level 5 to 10 procedure, with the exception of the change in accelerator voltage. After all data were taken at power level 15, a thruster shutdown command was issued. The thruster shutdown was as expected. The data for the 80 and 120 VDC BBPPU input cases were identical to the data presented here.

After completing the $120 \mathrm{VDC}$ input cases, the thruster was shut down, and the electrical lead to the neutralizer keeper lead was removed. The BBPPU was then commanded to start the thruster. The neutralizer failed to ignite and the BBPPU recycled back and re-entered the cathode heat period. After three attempts to light the thruster, the BBPPU sent the appropriate failure message to the data terminal and shut down. Following the shutdown, the neutralizer keeper lead was attached.

The thruster was restarted and throttled up to power level 10. While the thruster was operating in the steady state mode, the input voltage to the BBPPU was varied from $80-120$ VDC in 20 seconds. No discernable effects on the thruster were noted. The input voltage was returned to $100 \mathrm{VDC}$ and a shorting bar was applied from the thruster anode to the facility ground. The reaction of the BBPPU shown in Figure 9. While the anode was shorted to ground, the BBPPU recycled and attempted to return to the steady state. Each time the high voltage was applied to the thruster, large beam and accelerator currents resulted due to the short, forcing the BBPPU to recycle again. Approximately twenty recycles occurred. During this time period, the discharge current remained at the $4 \mathrm{~A}$ recycle cutback level and was stable. Similarly, the neutralizer keeper current was unaffected by the thruster fault. When the fault was cleared, the beam current returned to its value prior to the fault without overshoot.

Finally, the thruster was restarted to determine the length of time needed to start the thruster and throttle up to power level 15 . This would be the likely condition of interest for an earth orbital application. The results of this test are shown in Figure 10. Following the six minute preheat, the thruster was operating at full power in under three minutes. Throttle up was smooth and free of recycles, with no overshoot in beam current. It should be noted here that the throttling time could be decreased significantly by increasing the maximum allowable step in discharge current from $100 \mathrm{~mA}$ to a higher value. The maximum allowable step was not determined in the execution of this test.
Two anomalies were noted in the FIT, both having to do with oscillations in the neutralizer keeper and discharge current. A $300 \mathrm{kHz}$, nearly sinusoidal oscillation of $1 A_{p-p}$ amplitude was noted in the neutralizer keeper current. The AC component of the neutralizer keeper current is shown in Figure 11. The magnitude of oscillation was somewhat proportional to the beam current. The normal neutralizer keeper current ripple is a $100 \mathrm{kHz}$ sawtooth of approximately 100 $\mathbf{m A} A_{p-p}$ amplitude. The cause of this oscillation was found to be a failed diode in the high voltage pulse ignitor circuit. The diode failure allowed the pulse shaping capacitor to resonate with the output filter inductor of the neutralizer power supply. The result was the $300 \mathrm{kHz}$ oscillation. Further investigation showed that the diode was of marginal rating and was replaced with a more appropriate device. Following the diode replacement, the neutralizer keeper current returned to normal as shown in Figure 12.

Following the diagnosis and repair of the neutralizer keeper power supply, it was suspected that the discharge power supply had suffered a similar fault. The discharge current waveform was expected to be similar to that of the neutralizer keeper current, with a peak-to-peak amplitude of $500 \mathrm{~mA}$ at full power. However, as shown in Figure 12, the discharge current was sinusoidal in shape. Further, the magnitude of the oscillation was $2 \mathrm{~A}_{\mathrm{p}-\mathrm{p}}$ at full power. Inspection of the start circuit revealed no failures. Subsequently, a circulating current was discovered in bypass capacitors which were installed from the outputs of the BBPPU to ground to eliminate common mode noise from the telemetry and microcontroller interface circuits. When these capacitors were appropriately isolated from the thruster with resistors, the circulating current no longer flowed and the discharge current returned to normal.

\section{Conclusions}

The Functional Integration Test was the final development test of the NSTAR BBPPU and Engineering Model Thruster prior to their delivery to NASA JPL for an 8000 hour wear test. The BBPPU contained all power supplies necessary to operate the thruster and a microcontroller which sequenced the power supplies to automate the thruster ignition and cathode conditioning procedures. The controller also regulated the beam current about a setpoint and throttled the engine over a $0.5-2.3 \mathrm{~kW}$ power range. The stability of these routines and the BBPPU power supplies was verified over the full input voltage range 
of the breadboard.

The automated sequences were conducted without incident. The thruster started reliably and transitioned smoothly to steady state at all input power conditions. The beam current regulation loop maintained stability under all conditions tested. Throttling was accomplished without overshoot. Maximum time for a throttle up from low power to full power was under three minutes.

The BBPPU also correctly detected and reacted to several different thruster faults. All high voltage transient fault conditions resulted in nominal BBPPU responses, and a manually induced, continuous thruster fault did not damage the BBPPU. When the fault was removed, the BBPPU restored the thruster to the steady state condition without overshoot in beam current. Failed start attempts and input bus failures resulted in a proper, orderly shutdown of the BBPPU and safing of the thruster.

Two anomalies, manifested as neutralizer keeper and discharge current oscillations, were noted during the FIT. These were traced to failed components and improper telemetry circuit common mode filter designs. Repairs and design changes eliminated these anomalies and restored the BBPPU to nominal operation.

The FIT successfully concluded, and the BBPPU/EMT delivered for integration into a planned $8000 \mathrm{hr}$ test. All data and "lessons learned" were entered into the NSTAR thruster development database, and also transferred to the flight hardware contractor.

\section{Acknowledgements}

The authors wish to thank Messrs. Stanley Krauthamer and David Rogers of JPL for their continued assistance in the development of the NSTAR BBPPU. The authors also extend special thanks to Mr. G.I. "Hap" Cardwell of Cardwell Associates Inc. for his assistance in the diagnosis of the discharge current anomaly.

\section{References}

1. Kakuda, R., Sercel, J., and Lee, W., "Small Body Rendezvous Mission Using Solar Electric Ion Propulsion: Low Cost Mission Approach and Technology Requirements," IAA Paper L-0710, April 1994.

2. Janson, S.W., "The On-Orbit Role of Electric Propulsion," AIAA Paper 93-2220, June 1993.

3. Patterson M.J., et al., " $2.3 \mathrm{~kW}$ Ion Thruster Wear Test," AIAA Paper 95-2516, July 1995.
4. Patterson, M.J., et al., "NASA $30 \mathrm{~cm}$ Ion Thruster Development Status," AIAA Paper 94-2849, June 1994, (Also NASA TM-106842).

5. Soulas, G.C., "Multiple Hollow Cathode Wear Testing for the Space Station Plasma Contactor," AIAA Paper 94-3310, June 1994.

6. Sarver-Verhey, T.R., "Continuing Life Test of a Xenon Hollow Cathode for a Space Station Plasma Contactor," AIAA Paper 94-3312, June 1994.

7. Sarmiento, C.J., and Gruber, R.P., "Low Power Arcjet Pulse Ignition," NASA TM-100123, July, 1987. 8. Hamley, J.A., et al., "A 2.5kW Power Processor for the NSTAR Ion Propulsion Experiment," AIAA Paper 94-3305, July 1994.

9. Hamley, J.A., et al., "Development Status of the NSTAR Ion Propulsion System Power Processor," AIAA Paper 95-2517, July 1995.

10. Biess, J.J., Inouye, L.Y., and Schoenfeld, A.D., "Electric Prototype Power Processor for a 30-cm Ion Thruster," NASA CR-135287, 1978.

11. Herron, B.G., et al., 30-cm Ion Thruster Power Processor," NASA CR-135401, 1978.

12. Polk, J.E., "A 1000 Hour Wear Test of the NASA 30-cm Xenon Ion Thruster," AIAA Paper 96-2717, to be published.

13. Grisnik, S.P., and Parkes, J.E., "A Large, High Vacuum, High Pumping Speed Space Simulation Chamber for Electric Propulsion," IEPC-93-151, September 1993. 
Table 1. Sample NSTAR power throttling table. Levels 0 through 15 shown in descending order. Asterisks indicate levels tested during the FIT. A † denotes a controlled parameter

\begin{tabular}{|c|c|c|c|c|c|c|c|}
\hline Power & Beam & Beam & Dis. & Dis & Neut. & Neut. & Power, \\
\hline Level & Volt., V† & Curr., At & Volt., V & Curr., A & Volt., V & Curr., A & $w$ \\
\hline $15^{*}$ & 1100 & 1.78 & 28.0 & 10.8 & 14 & 1.5 & 2288 \\
\hline 14 & 1100 & 1.68 & 28.0 & 10.1 & 14 & 1.5 & 2159 \\
\hline 13 & 1100 & 1.58 & 28.0 & 9.4 & 14 & 1.5 & 2029 \\
\hline 12 & 1100 & 1.48 & 29.0 & 8.7 & 14 & 1.5 & 1908 \\
\hline 11 & 1100 & 1.38 & 29.0 & 8.0 & 15 & 1.5 & 1780 \\
\hline $10^{*}$ & 1100 & 1.28 & 30.0 & 7.4 & 15 & 1.5 & 1660 \\
\hline 9 & 1100 & 1.17 & 30.0 & 6.8 & 15 & 1.5 & 1521 \\
\hline 8 & 1100 & 1.07 & 30.0 & 6.2 & 16 & 1.5 & 1395 \\
\hline 7 & 1100 & 0.97 & 31.0 & 5.6 & 16 & 1.5 & 1273 \\
\hline 6 & 1100 & 0.86 & 31.0 & 5.0 & 16 & 1.5 & 1133 \\
\hline $5 *$ & 1100 & 0.66 & 31.5 & 4.4 & 18 & 1.5 & 901 \\
\hline 4 & 1100 & 0.64 & 32.0 & 4.2 & 20 & 1.5 & 878 \\
\hline $3 *$ & 1100 & 0.54 & 32.0 & 4.0 & 22 & 1.5 & 766 \\
\hline $2 *$ & 850 & 0.54 & 32.0 & 4.0 & 24 & 1.5 & 635 \\
\hline $1 *$ & 650 & 0.54 & 32.0 & 4.0 & 24 & 1.5 & 527 \\
\hline 0 & 0 & 0 & 0 & 0 & 0 & 0 & 0 \\
\hline
\end{tabular}

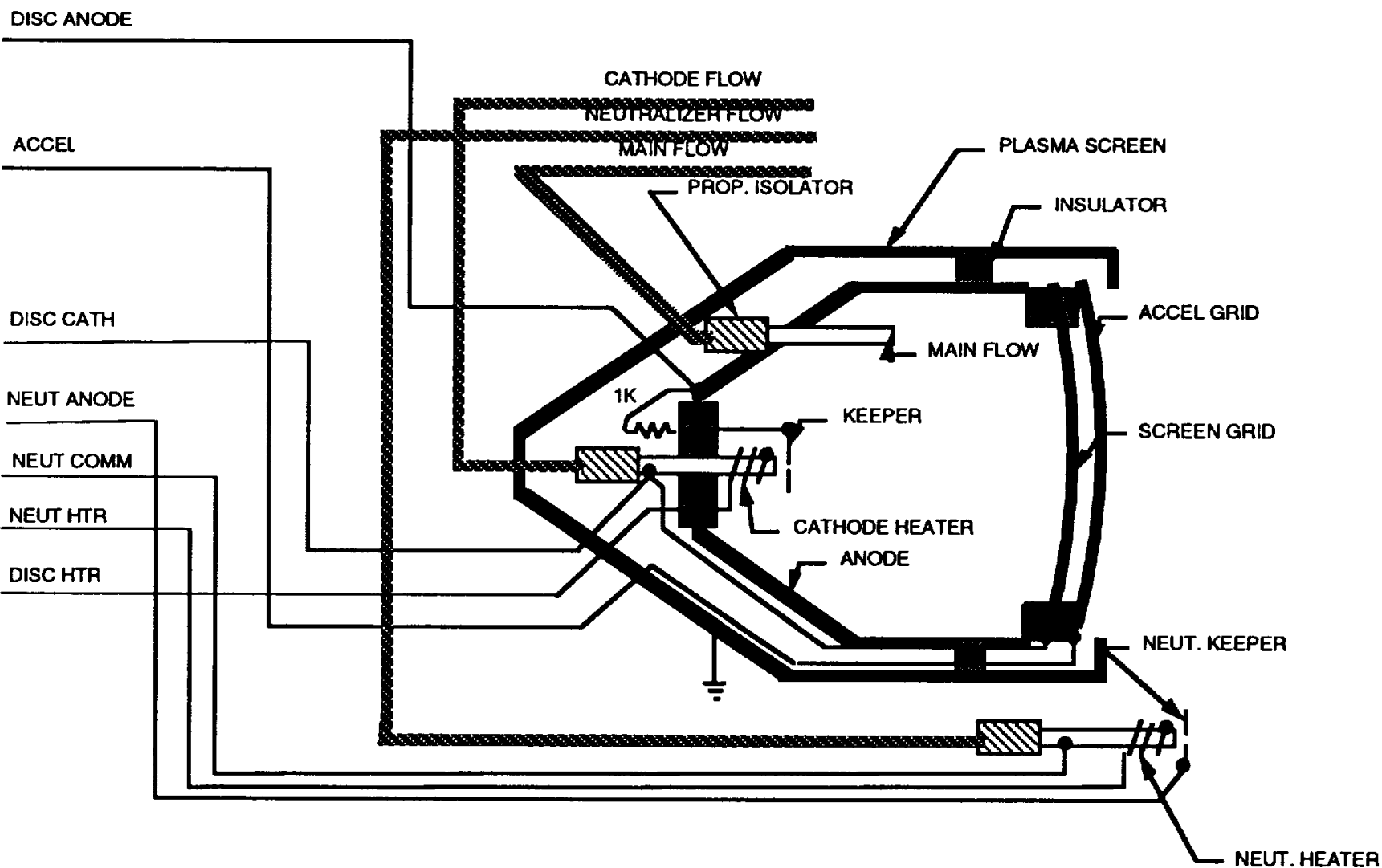

Figure 1. NSTAR thruster schematic diagram. The plasma screen was isloated from facility ground for the FIT. 


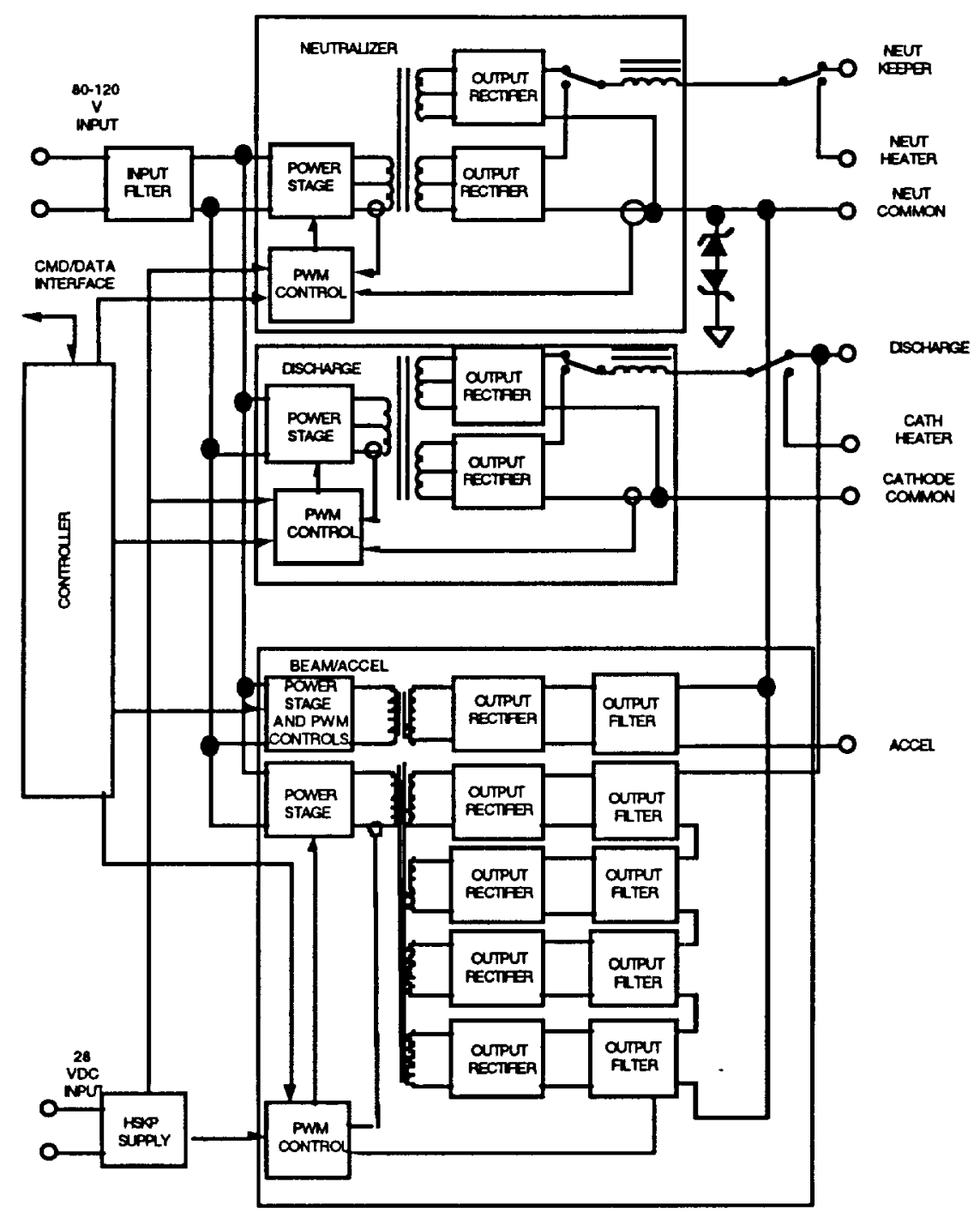

Figure 2. NSTAR breadboard PPU block diagram.

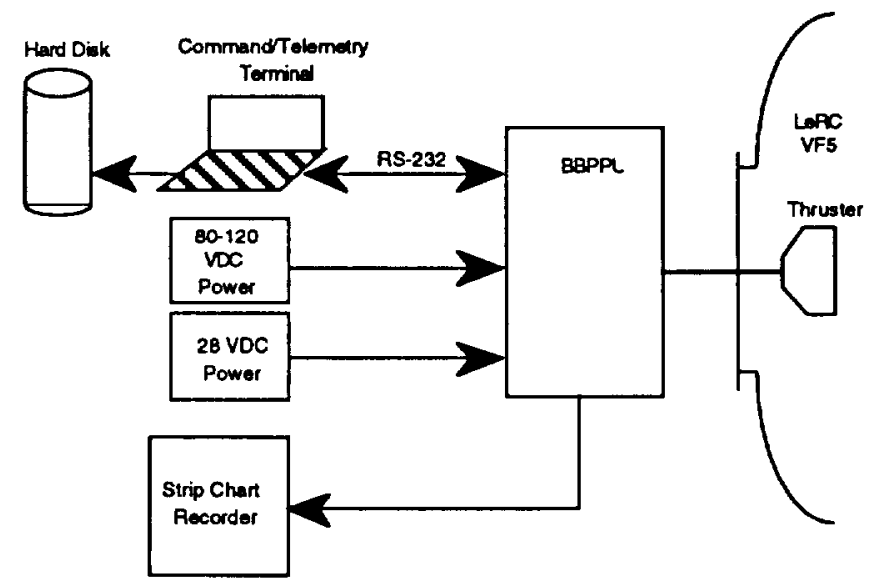

Figure 3. FIT electrical setup 


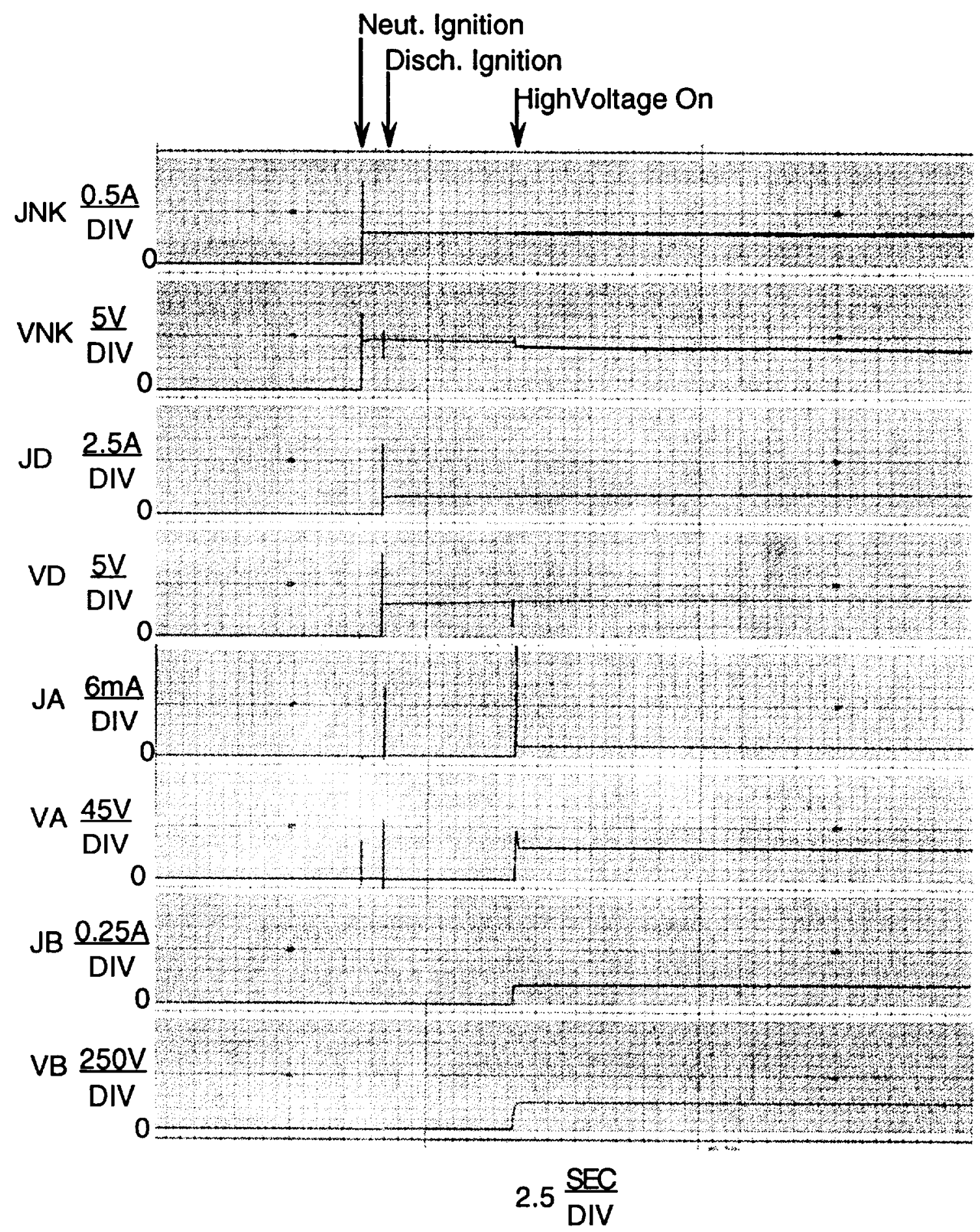

Figure 4. Thruster Start at 100 VDC input 


\section{Flow Adjustment}
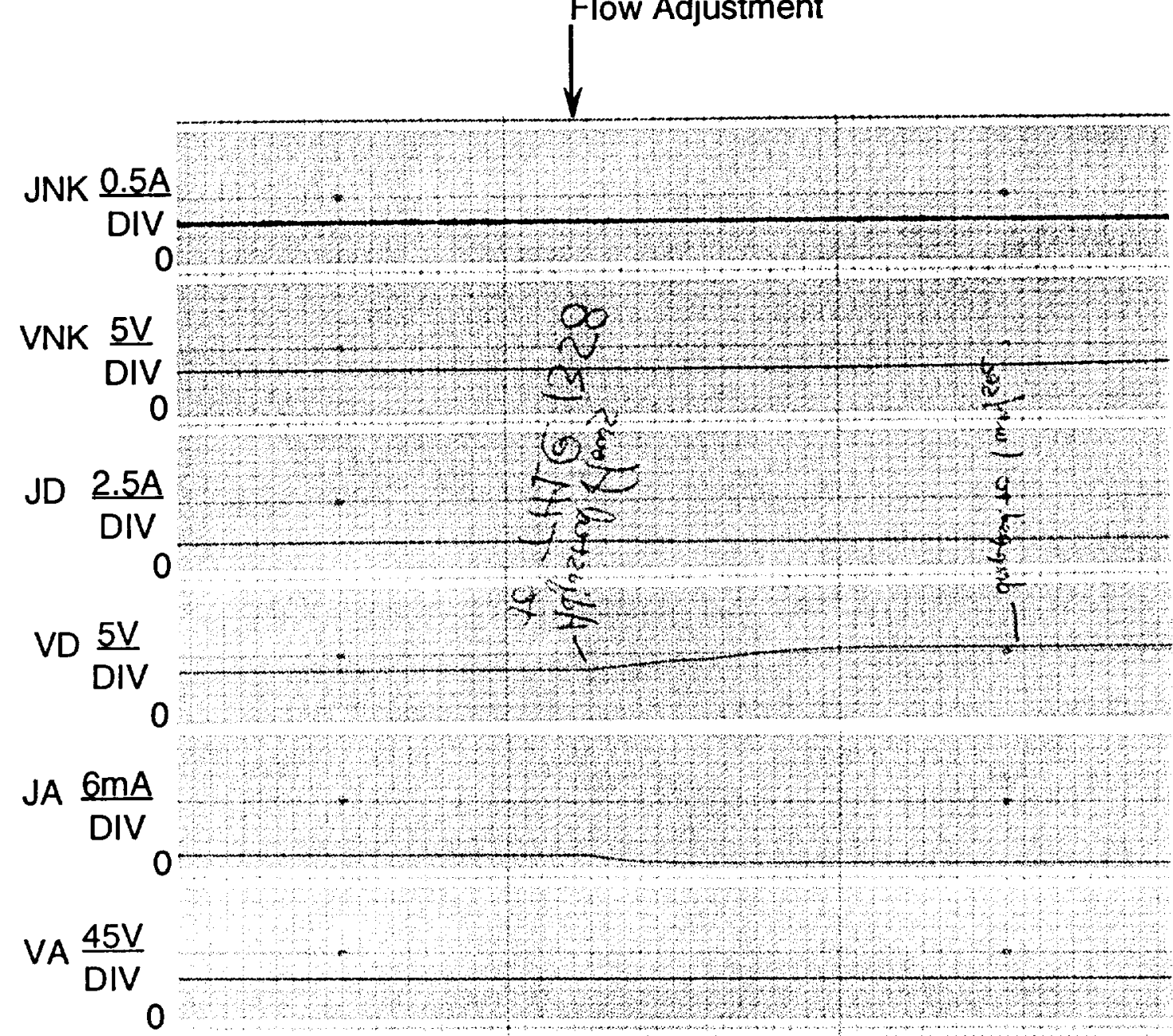

JB $\frac{0.25 A}{\text { DIV }}$

VB $\frac{250 \mathrm{~V}}{\mathrm{DIV}}$

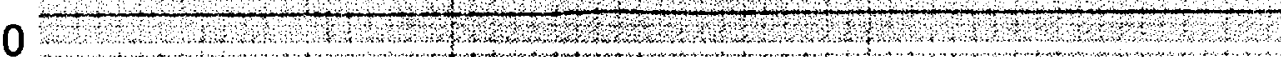

0

\section{$2.5 \frac{\text { SEC }}{\text { DIV }}$}

Figure 5. Flow adjustment from augmented thruster start flow to the nominal operating flow for power level 1. 


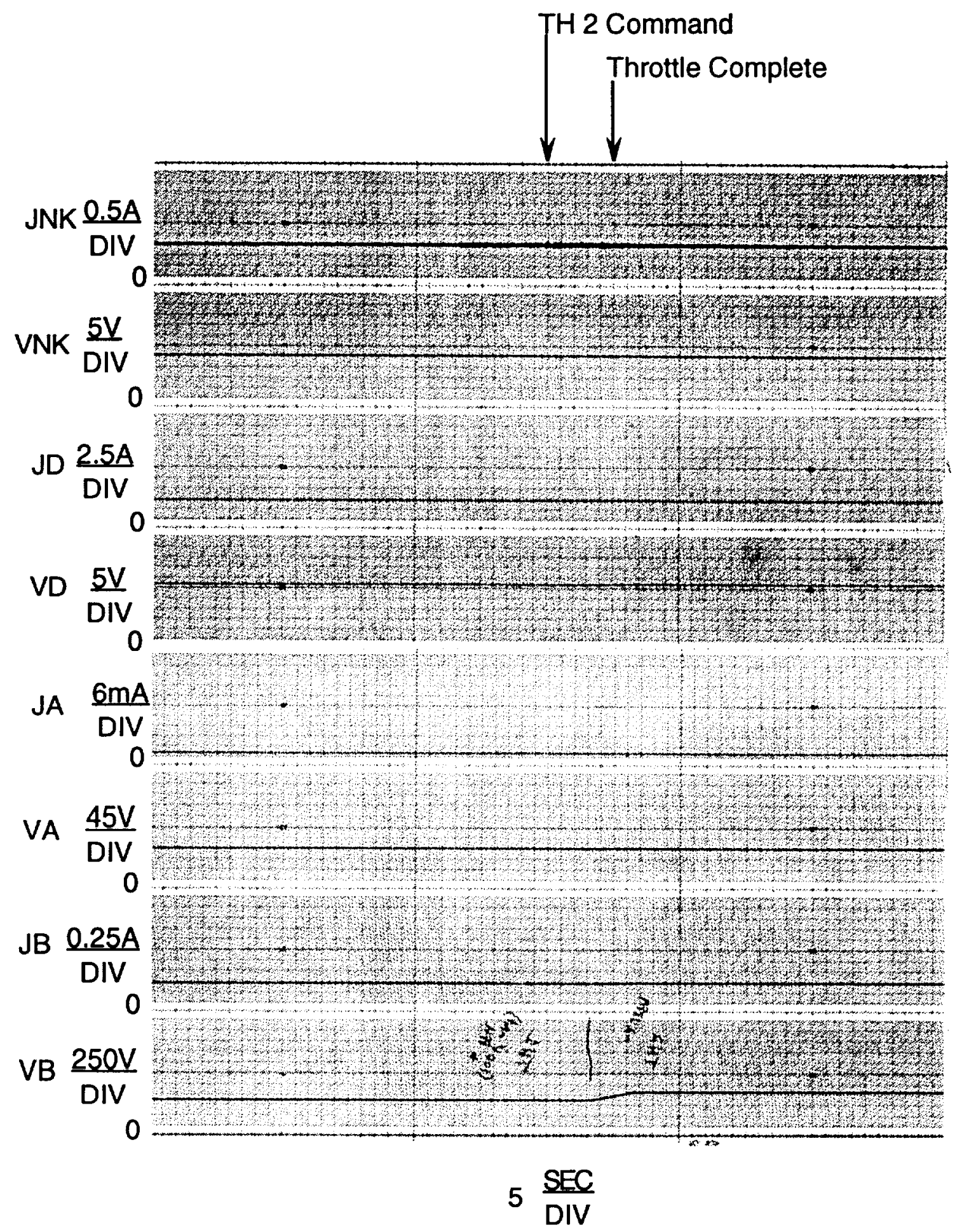

Figure 6. Throttle up from power level 1 to power level 2. 


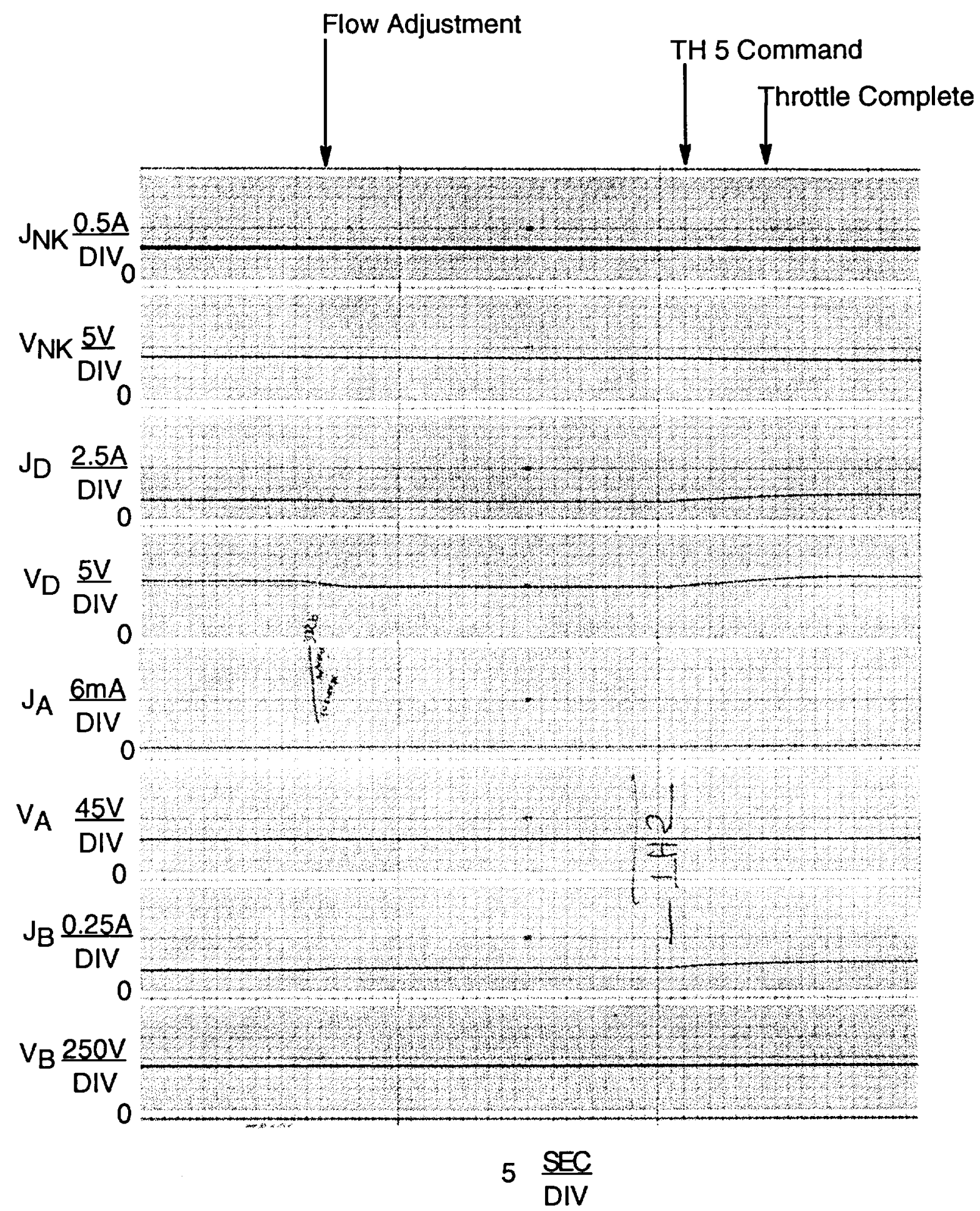

Figure 7. Throttle up from power level 3 to power level 5 


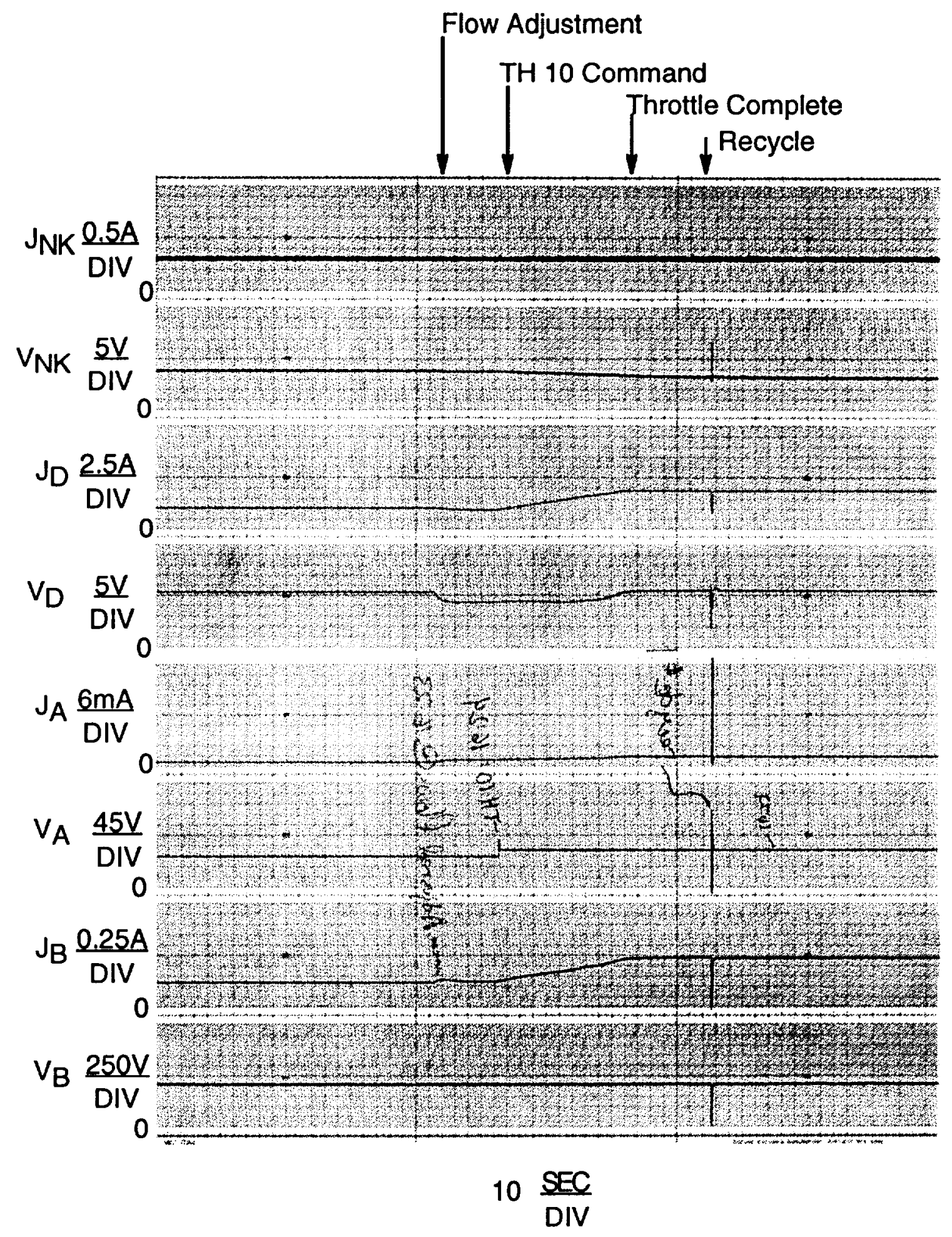

Figure 8. Throttle up from power level 5 to power level 10. 


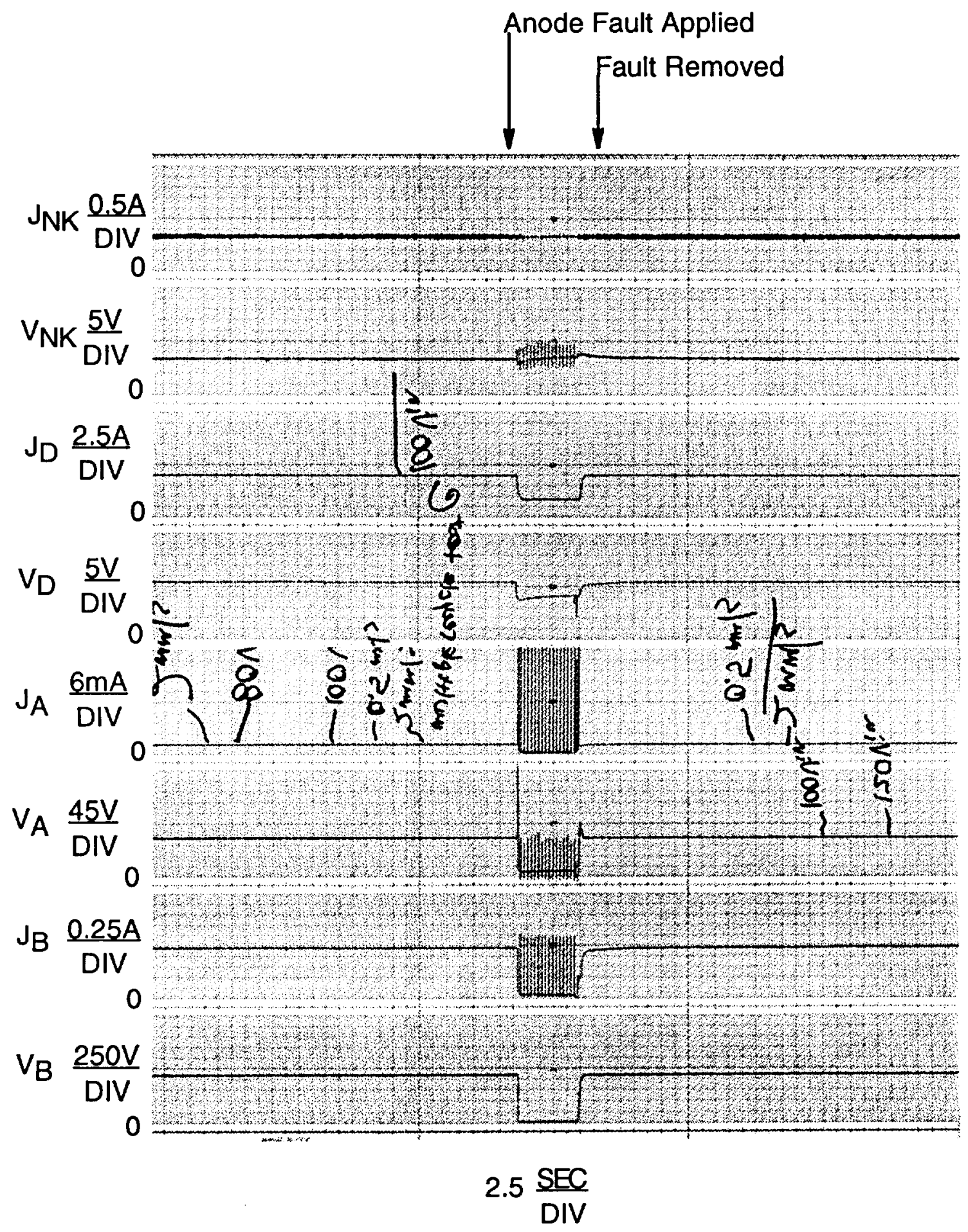

Figure 9. Continuous recycles. 


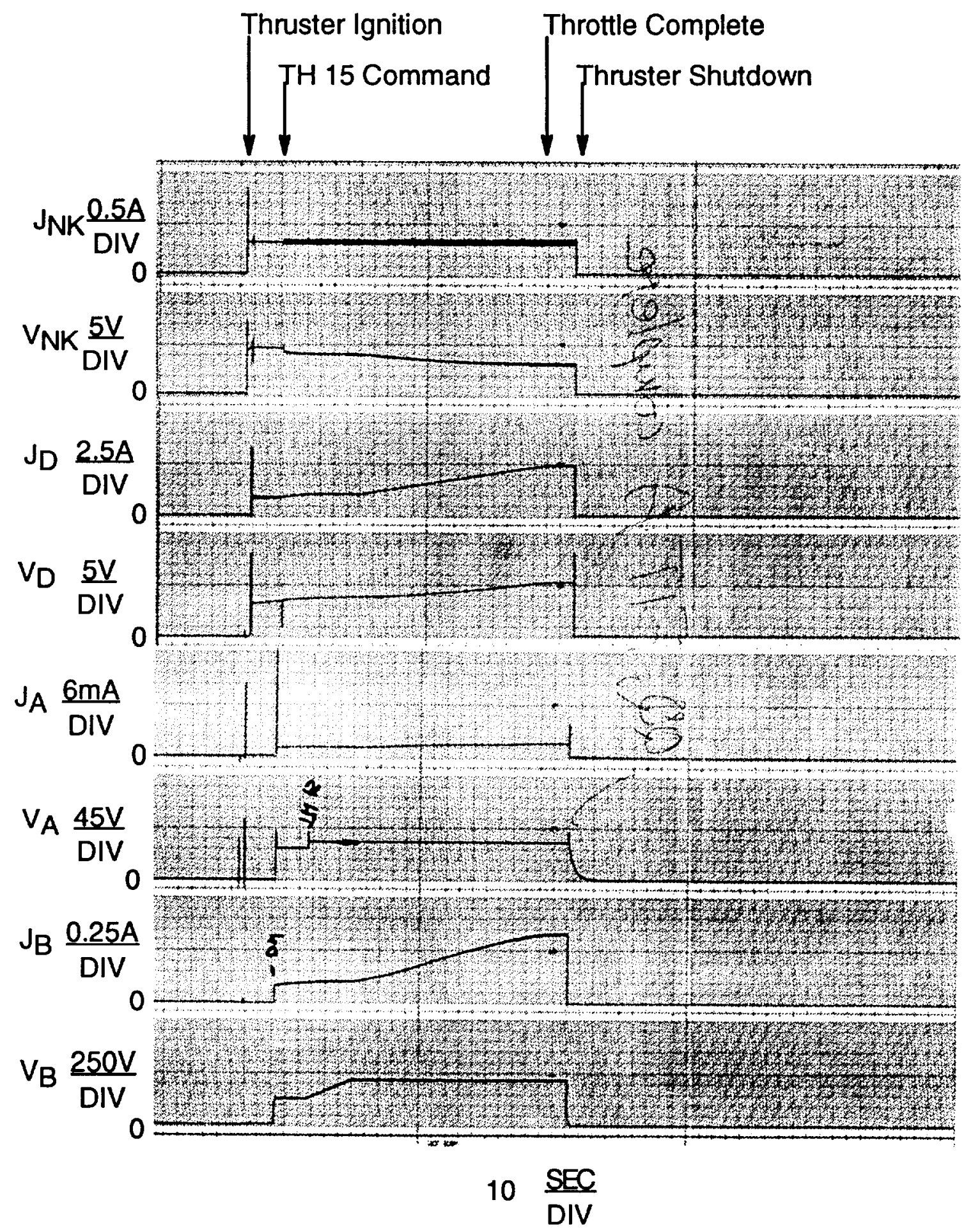

Figure 10. Throttle up from power level 1 to 15 


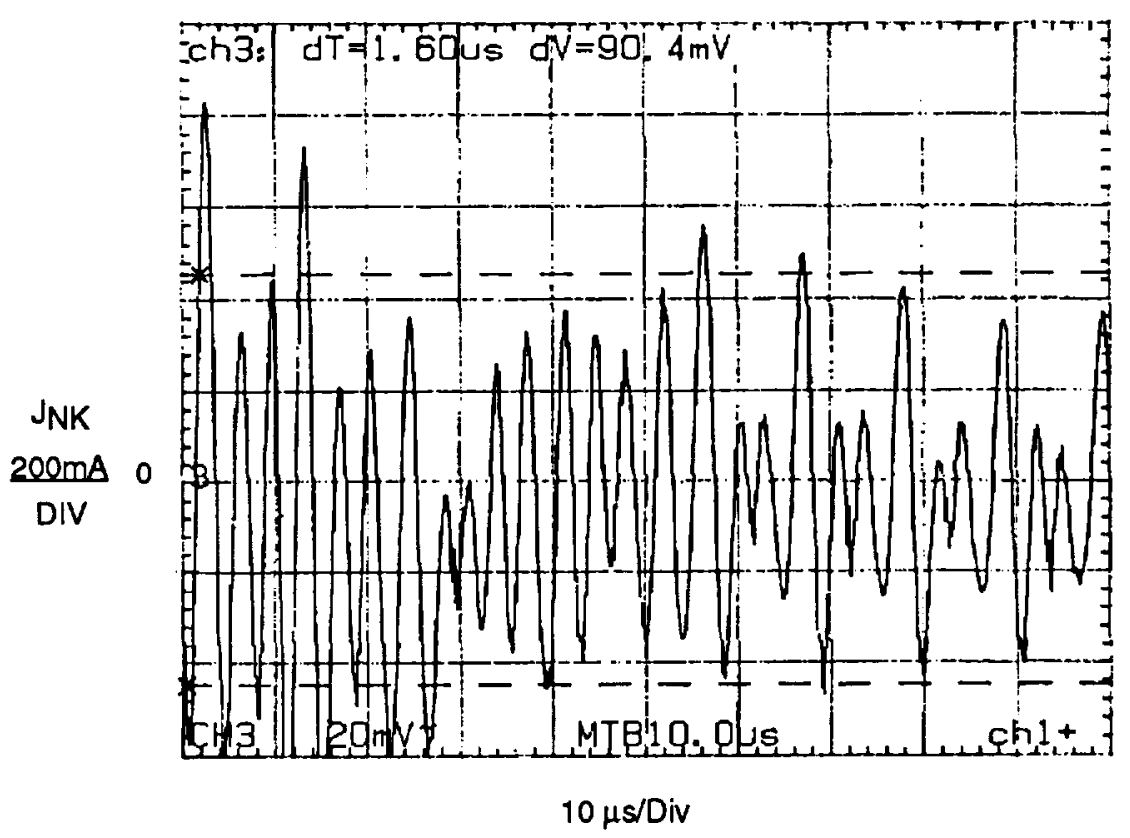

Figure 11. Neutralizer Keeper Current Oscillations

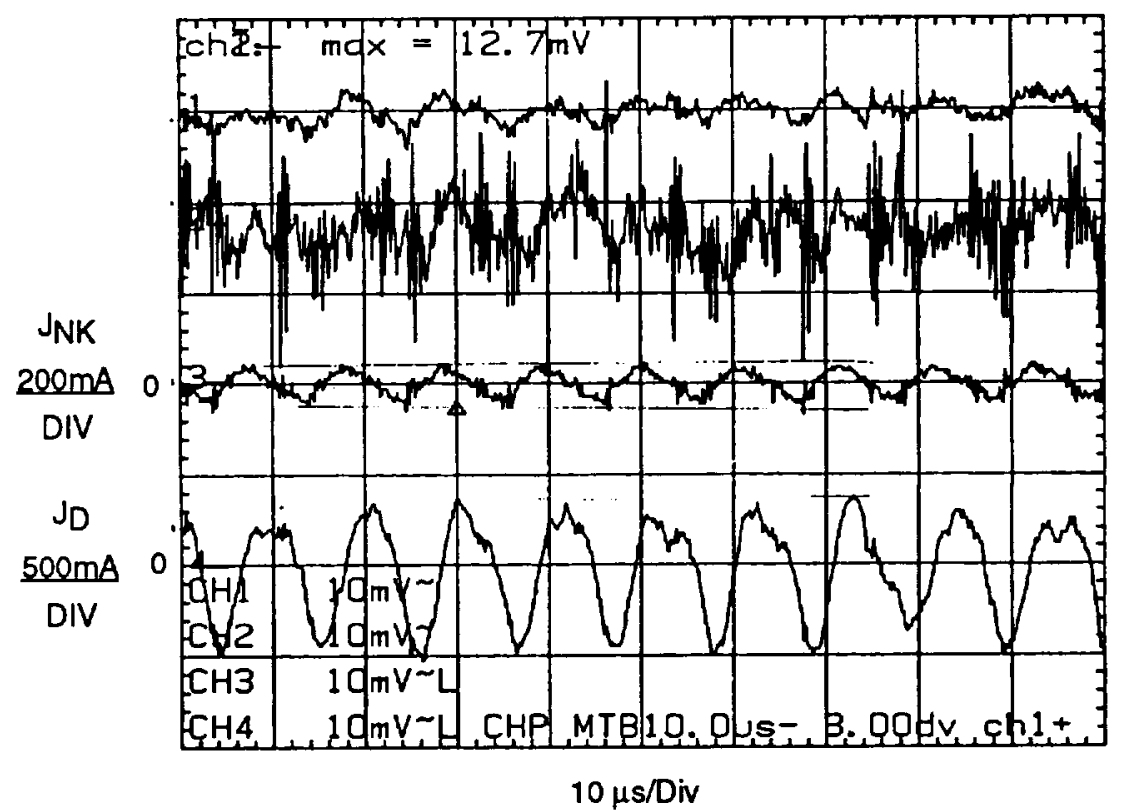

Figure 12. Nominal neutralizer keeper current and discharge current with oscillations 


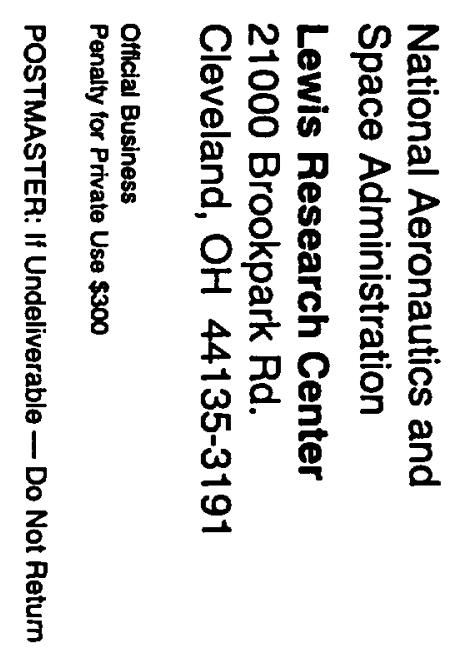

